OPEN ACCESS

Edited by: Angelo Silverio,

University of Salerno, Italy

Reviewed by:

Konstantinos Stathogiannis, Stanford University, United States

Panagiotis Xaplanteris,

Université Libre de Bruxelles, Belgium

*Correspondence: Julian P. Gunn j.gunn@sheffield.ac.uk

Specialty section:

This article was submitted to Structural Interventional Cardiology,

a section of the journal

Frontiers in Cardiovascular Medicine

Received: 01 July 2021

Accepted: 22 September 2021

Published: 22 October 2021

Citation:

Haley HA, Ghobrial M, Morris $P D$,

Gosling R, Williams G, Mills MT, Newman T, Rammohan $V$

Pederzani G, Lawford PV, Hose R and Gunn JP (2021) Virtual (Computed) Fractional Flow Reserve: Future Role

in Acute Coronary Syndromes.

Front. Cardiovasc. Med. 8:735008

doi: $10.3389 / f C V m .2021 .735008$

\section{Virtual (Computed) Fractional Flow Reserve: Future Role in Acute Coronary Syndromes}

\author{
Hazel Arfah Haley 1,2,3, Mina Ghobrial ${ }^{1,2}$, Paul D. Morris ${ }^{1,2,3}$, Rebecca Gosling ${ }^{1,2}$, \\ Gareth Williams s,2, Mark T. Mills ${ }^{1,3}$, Tom Newman ${ }^{1,3}$, Vignesh Rammohan ${ }^{1,2}$, \\ Giulia Pederzani ${ }^{1,2}$, Patricia V. Lawford ${ }^{1,2}$, Rodney Hose ${ }^{1,2}$ and Julian P. Gunn ${ }^{1,2,3 *}$ \\ ${ }^{1}$ Department of Infection Immunity and Cardiovascular Disease, University of Sheffield, Sheffield, United Kingdom, ${ }^{2}$ Insigneo \\ Institute for in silico Medicine, Sheffield, United Kingdom, ${ }^{3}$ Sheffield Teaching Hospitals National Health Service Foundation \\ Trust, Sheffield, United Kingdom
}

The current management of acute coronary syndromes (ACS) is with an invasive strategy to guide treatment. However, identifying the lesions which are physiologically significant can be challenging. Non-invasive imaging is generally not appropriate or timely in the acute setting, so the decision is generally based upon visual assessment of the angiogram, supplemented in a small minority by invasive pressure wire studies using fractional flow reserve (FFR) or related indices. Whilst pressure wire usage is slowly increasing, it is not feasible in many vessels, patients and situations. Limited evidence for the use of FFR in non-ST elevation (NSTE) ACS suggests a $25 \%$ change in management, compared with traditional assessment, with a shift from more to less extensive revascularisation. Virtual (computed) FFR (vFFR), which uses a 3D model of the coronary arteries constructed from the invasive angiogram, and application of the physical laws of fluid flow, has the potential to be used more widely in this situation. It is less invasive, fast and can be integrated into catheter laboratory software. For severe lesions, or mild disease, it is probably not required, but it could improve the management of moderate disease in 'real time' for patients with non-ST elevation acute coronary syndromes (NSTE-ACS), and in bystander disease in ST elevation myocardial infarction. Its practicability and impact in the acute setting need to be tested, but the underpinning science and potential benefits for rapid and streamlined decision-making are enticing.

Keywords: computed blood flow, ACS - ACS/NSTEMI, FFR, vFFR, virtual FFR, angiogram based FFR, coronary artery modelling

\section{WHAT ARE THE ISSUES WITH CORONARY ANGIOGRAPHY IN ACS?}

The fundamental limitation of CAG is that it is an anatomical, not a physiological, test which reveals luminal stenoses, with a poor relationship to blood flow and the identification of "significant" coronary artery disease (1). The severity of an angiographic lesion is typically over-estimated by eye, and the length under-estimated (2). There is also considerable inter-observer variability in lesion assessment (3). These weaknesses are only partly addressed by using quantitative coronary angiography, which has its own limitations (4). In addition, assessment is critically dependent upon the quality of the angiographic images; inadequate contrast, insufficient projections, overlapping 
vessels, excess movement, and lesions located at ostia, branch points and in series pose particular challenges. In addition, it cannot reveal the vulnerability or instability of lesions without the assistance of intravascular imaging, although this is also a limitation of physiological assessment (5).

\section{WHAT IS PHYSIOLOGICAL GUIDANCE?}

Fractional flow reserve (FFR) is the ratio of the maximum achievable blood flow in the stenotic coronary artery to the theoretical maximum flow in an equivalent normal coronary artery:

$$
F F R=\frac{Q \text { with stenosis }}{Q \text { normal }}=\frac{\left(\left(\boldsymbol{P}_{d}-P_{v}\right) / R\right)}{\left(\left(\boldsymbol{P}_{a}-P_{v}\right) / R\right)} \approx \frac{P_{d}}{\boldsymbol{P}_{a}}
$$

where $\mathrm{Pa}$ is mean aortic (proximal) pressure, $\mathrm{Pd}$ is pressure distal to the stenosis, $\mathrm{Pv}$ is the central venous pressure and $\mathrm{R}$ is resistance to flow. FFR approximates to the ratio of the distal to proximal pressure, so it can be measured with a pressuresensitive angioplasty guidewire. FFR is best calculated during maximum hyperaemia, during which microvascular resistance (MVR) is assumed minimal or constant which can be achieved by an infusion of adenosine (see Figure 1).

FFR, or related 'resting' indices such as resting full cycle ratio (RFR) or instantaneous wave-free ratio (iFR), is recommended in arteries with narrowing estimated visually between 50 and $90 \%$, when non-invasive testing is unavailable or inconclusive (6). An FFR $<0.80$ is the accepted threshold for ischaemia and justifies intervention. Physiological guidance, compared with angiography alone, reduces symptom burden, repeat revascularisation and health expenditure at the time of percutaneous coronary intervention (PCI) (7-9). A hidden benefit of physiological guidance is that, perhaps unfortunately, angiographic precision is not essential.

\footnotetext{
Abbreviations: AUC, Area under the operator receiving curve; AHA, American heart association; ACS, Acute coronary syndrome; CABG, Coronary artery bypass grafting; CAD, Coronary artery disease; CAG, Coronary angiography; CAFFR, Coronary angiography based FFR; CAAS-vFFR, Cardiovascular angiographic analysis system for vessel FFR; CCL, Cardiac catheter laboratory; CCS, Chronic coronary syndrome; CFD, Computational fluid dynamics; CT, Computed tomography; CTCA, CT coronary angiography; CT-FFR, CT fractional flow reserve; COMPLETE, Complete revascularisation with multivessel PCI for myocardial infarction; COMPARE-ACUTE, Fractional flow reserve-guided multivessel angioplasty in myocardial infarction; DANAMI-3-PRIMULTI, Complete revascularisation vs. treatment of the culprit lesion only in patients with ST-segment elevation myocardial infarction and multivessel disease; ESC, European Society of Cardiology; FAME, Fractional flow reserve vs. angiography for multivessel evaluation; FFR, Fractional flow reserve; FFR $_{\text {sim }}$, Simplified model of FFR calculation; FLOWER-MI, Multivessel PCI guided by FFR or angiography for MI; IFR, Instantaneous wave free ratio; MACE, Major adverse cardiovascular events; mFFR, Measured fractional flow reserve; MI, Myocardial infarction; MVD, Multi vessel disease; MVR, Microvascular resistance; NPV, Negative predictive value; NSTEMI, Non-ST elevation myocardial infarction; NSTE-ACS, Non-ST elevation acute coronary syndrome; PCI, Percutaneous coronary intervention; PPV, Positive predictive value; RCT, Randomised control trial; RFR, Resting full cycle ratio; STEMI, ST elevation myocardial infarction; TIMI, Thrombolysis in myocardial infarction; vFAI, Virtual functional assessment index; vFFR, Virtual fractional flow reserve; QALY, Quality adjusted life year; QCA, Quantitative coronary angiography; QFR, Quantitative flow ratio.
}

\section{WHAT IS THE EVIDENCE FOR FFR IN NSTE-ACS?}

Whilst the majority of the evidence for FFR is in chronic coronary syndromes (CCS), there were large NSTE-ACS subsets in some of the seminal studies. In the FAME study, 30\% of patients had NSTE-ACS. The 2-year rate of major adverse cardiovascular events (MACE) was significantly reduced in the FFR- vs. the CAG-guided groups, with no difference between the CCS and NSTE-ACS cohorts (10). Importantly, the study also showed that no myocardial infarctions (MI)s occurred in the FFR-guided deferred lesions in the NSTE-ACS cohort at 2 year follow up (11). A health economic analysis from the study also revealed that FFR-guided PCI improved outcomes and costs at 1 year when compared with the CAG-guided approach (12). In a "real-world" observational study of 3,000 patients with ACS, a lower in-hospital mortality was observed for FFR guidance than for a CAG-based approach (1.1 vs. $3.1 \%, p<0.01)$, and reductions in hospital stay, acute kidney injury (AKI) and bleeding (13). In a study of 350 ACS patients randomised to FFR- vs. CAG-guidance, disclosure of the FFR resulted in changed management in $21.6 \%$ of cases, reducing the number of unnecessary procedures and downstream unplanned revascularizations (14). A cost-effectiveness assessment disclosed that increased up-front costs (pressure wire use and laboratory time) were more than compensated by later savings in subsequent hospital stay, events and procedures; and there was also a small benefit in quality-adjusted life year (QALYs) (15). In another study of 107 patients with multi-vessel disease and moderate non-culprit lesions, FFR resulted in $76 \%$ of patients not being revascularised; and importantly there was no MACE in this group (16). A meta-analysis of the three major RCTs also concluded that FFR guidance in patients with NSTE-ACS led to a reduction in the rate of MI without any difference in death or all-cause mortality and target vessel revascularisation compared with CAG guided approach (17). In a study of 1,983 patients with ACS $(n=533)$ and CCS $(n=1,450)$, FFR led to a similarly high percentage of reclassification of treatment in both groups (ACS $=38 \%$ vs. CCS $=39 \%$ ). In the ACS patients, FFR guidance led to a change from revascularization in $70 \%$ and medical therapy in $30 \%$ to revascularisation in $38 \%$ and medical therapy in $62 \%$. There was no significant difference in MACE (8.0 vs. $11.6 \% ; p=0.20)$ or symptoms (92.3 vs. $94.8 \%$ angina free; $p=0.25$ ) between the reclassified (FFR discordant with CAG) vs. the non-reclassified patients (FFR concordant with CAG) groups. FFR-guided deferral to medical therapy in the ACS group was as safe as in the CCS group (MACE 8 vs. $8.5 \%$; revascularization 3.8 vs. $5.9 \%$; and freedom from angina 93.6 vs. $90.2 \%$ ). Worse outcomes were observed in the six percent of patients in whom FFR was disregarded (18). In a study of 1,596 patients of which 301 had ACS ( $n=449$ lesions), deferral of the non-culprit lesion based upon FFR resulted in a MACE 3.8\% (ACS) vs. $1.6 \%$ (CCS), mainly driven by ischaemia-driven revascularisation ( 2.8 vs. 1.1\%) (19). Two systematic reviews comparing available data on FFR guidance confirmed this difference, with no significant difference in mortality $(20,21)$. ESC guidelines propose that FFR 

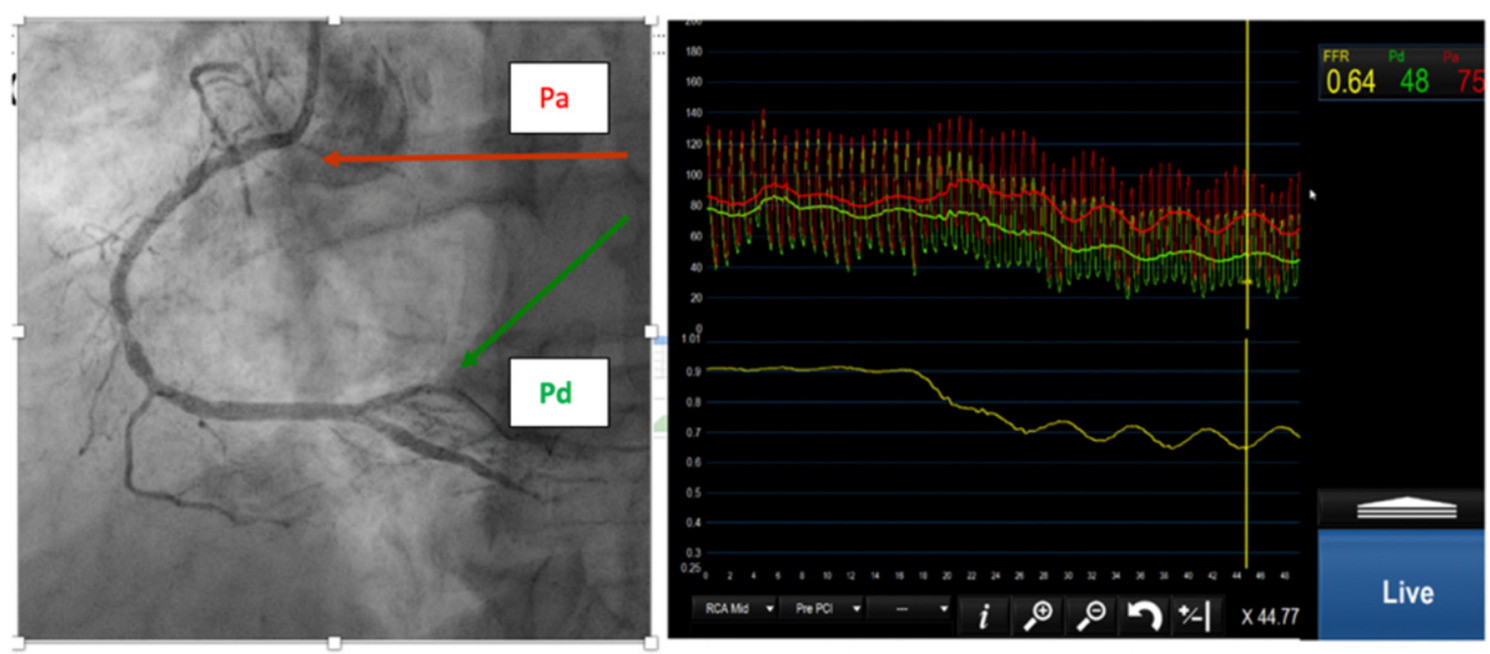

FIGURE 1 | (Left) Right coronary angiogram with moderate stenoses. (Right) Proximal (red) and distal (green) pressure. The FFR is 0.64.

can be used in ACS (class IIb) to assist decision-making in nonculprit lesions whose severity is moderate (22), which contrasts with the recommendation to use FFR in intermediate stenoses in CCS (Class I) for patients with multi-vessel disease (MVD) (class IIa) (23).

\section{DOES FFR HAVE A ROLE IN STEMI?}

FFR has no role in selecting the "culprit" vessel of ST elevation MI (STEMI), but it may be useful in assessing "bystander" stenoses. In COMPLETE, a landmark study of 4,041 STEMI patients with MVD, in which visual, rather than FFR guidance, was used, complete revascularization reduced the risk of cardiovascular deaths, $\mathrm{MI}$ and repeat revascularizations from 16.9 to $8.7 \%$ at 36 months when compared with a culpritonly-PCI approach; the benefit largely driven by a reduction in unplanned revascularization (24). In COMPARE-ACUTE (885 patients), DANAMI-3-PRIMULTI (627 patients) and FLOWERMI (1,171 patients), an FFR-guided approach, rather than a purely visual one was used. In COMPARE-ACUTE, the primary outcome (composite of all-cause mortality, non-fatal MI, revascularisations and cerebrovascular events) occurred in $20 \%$ of the culprit-only revascularization group vs. $8 \%$ in the FFR-guided complete revascularization group $(P<0.001)$ (25). In DANAMI-3-PRIMULTI, the equivalent figures were 22 and $13 \%$, respectively ( $p=0.004)(26)$. The risk of future cardiovascular events was mainly driven by a $69 \%$ reduction in repeat revascularizations. In contrast, in FLOWER-MI, an FFR-guided approach in the non-culprit lesions in STEMI was not found to be superior to an angiography-guided strategy at reducing the risk of death, MI or repeat revascularization at 1 year. PCI of non-culprit lesions was performed in $66 \%$ of patients with the FFR-guided strategy and in $97 \%$ with the angiography-guided strategy. The primary outcome occurred in
$5.5 \%$ (32 of 586 patients) in the FFR-guided approach vs. $4.2 \%$ ( 24 of 577 patients) in the angiographic-guided group $(p=0.31)$ (27). The difference was driven by a non-significant $77 \%$ higher risk of MI in patients assigned to the FFR group (18 patients in the FFR guided group vs. 10 patients in the angiographic guided group). The study was powered to detect a $37 \%$ lower risk of the primary composite outcome, but ultimately generated a wide confidence interval (hazard ratio, 1.32 ; 95\% CI $0.78-$ 2.23). In addition, intervention on the non-culprit lesions was encouraged to be performed at index presentation, rather than as a staged procedure. A larger RCT specifically addressing timing may be required. A parallel line of enquiry may be necessary to interrogate the hypothesis that conventional physiological assessment of bystander lesions may be of lesser importance than identifying vulnerable plaques.

\section{WHY DO WE USE SO LITTLE PHYSIOLOGY IN THE ACUTE CARDIAC CATHETER LABORATORY?}

Despite robust evidence supporting the use of FFR, in practise its use remains low, at $<10 \%$ of PCIs, and in an even smaller proportion of diagnostic angiograms; the majority being in patients with CCS $(2,28)$. This low uptake in the acute setting may reflect the time and cost associated with deploying a pressure wire. Also, if stenting a borderline lesion is likely to be straightforward, it may be felt that a "quick fix" is reasonable. This is not, however, a position supported by the evidence. Other reasons for under-use may include complex anatomy, such as tortuosity, angulation, calcification and diffuse disease, in which manipulating a pressure wire might be hazardous. There may also be a lack of awareness of the accumulating evidence in ACS confounded by pressure on the operator to make a swift therapeutic decision in response to situational factors. 


\section{IS FFR RELIABLE IN ACUTE MI?}

The validity of FFR in an acute MI has been questioned due to the possibility that blunted acute microvascular dysfunction might limit maximal hyperaemia, reducing the apparent physiological significance of a lesion (29). Does this mean that the FFR is "incorrect"? The value is indeed correct and reflects the current physiology, however the concern is that lesion significance may increase as the microvasculature recovers. Whilst this may be the case in a culprit lesion, in a study of 101 patients undergoing PCI for an acute MI (75 STEMI and 26 NSTEMI), the FFR measurements in 112 non-culprit vessels did not change between the acute presentation and follow up (30). In a study of 57 patients who had recovered from an MI an average 6 days previously, FFR $<0.75$ was associated with sensitivity of $82 \%$ and specificity of $87 \%$ vs. SPECT imaging, and the relationship between the microvascular resistance in the infarcted territory and the viable myocardium was inversely proportioned (31). Similar results were found in a separate study of 48 patients (32).

\section{PROBLEMS WITH FFR IN ACS}

FFR is based upon the assumption that the relationship between flow and pressure in healthy and diseased arteries is predictable from a linear relationship. This is not strictly true, because energy is lost through friction in the diseased artery (viscous losses), and there is acceleration of flow at the outlet, producing a curvilinear relationship, which may particularly affect the acute patient (33). Also, the microvascular resistance, a crucial influence upon FFR, may differ between individuals, and be influenced by clinical, procedural, and extrinsic factors, which may be poorly controlled in the acute patient (34-36). Prior MI, diabetes, left ventricular hypertrophy, poorly controlled hypertension, endothelial dysfunction, and raised central venous pressure or left ventricular end-diastolic pressure (37) can also contribute. Uncertainty of the measurement itself is also a feature. The reproducibility of a therapeutic decision is $>95 \%$ when the FFR is outside the $0.75-0.85$ range, but only about $50 \%$ when it is close to 0.80 (38). This is of importance in the angiographic "borderline" lesion, for which the FFR is often also borderline. Other limitations are the lack of randomised data studying the use of FFR in left main stem disease, and technical difficulties measuring ostial, serial and bifurcation lesions (39). Measured FFR, therefore, has not achieved routine use in the management of ACS.

\section{WHAT ABOUT CT AND CT-FFR IN ACS?}

Functioning as a "triple rule-out," CT can be used in the emergency department for patients with chest pain and no ECG changes to rule out severe coronary disease, acute aortic syndrome or pulmonary embolism (40). CT coronary angiography (CTCA) is useful at excluding significant CAD, with a negative predictive value (NPV) approaching $100 \%$ (41). In a study of 568 patients with suspected ACS, $84 \%$ were identified as low risk, discharged from hospital and had no adverse cardiac events at 30 days (42). In a study of 368 patients with chest pain and an inconclusive initial evaluation, CTCA showed that $50 \%$ of patients were free of CAD (43). Current ESC guidelines recommend CTCA as an alternative to invasive CAG in patients with low to intermediate risk of CAD and, when the troponin and ECG are inconclusive, to exclude ACS as class IIa (44). However, the RAPID-CTCA trial of 1,748 patients did not demonstrate a benefit of CTCA in reducing death, MI or stent thrombosis in suspected ACS when compared to standard practise (5.8 vs. $6.1 \% ; p=0.65$ ) (45). CTCA is limited at predicting the haemodynamic significance of a lesion. CT-FFR, however, can demonstrate ischaemia-provoking lesions by modelling the coronary vasculature and incorporating computational fluid dynamics (CFD) (46) with a diagnostic accuracy of $81 \%(47,48)$. CT-FFR is now recommended as an adjunct to CTCA in stable patients (49). It is limited, however, by the presence of calcification, tachycardia and arrhythmia (50). Other limitations are the availability of CT and, for CT-FFR, cost,

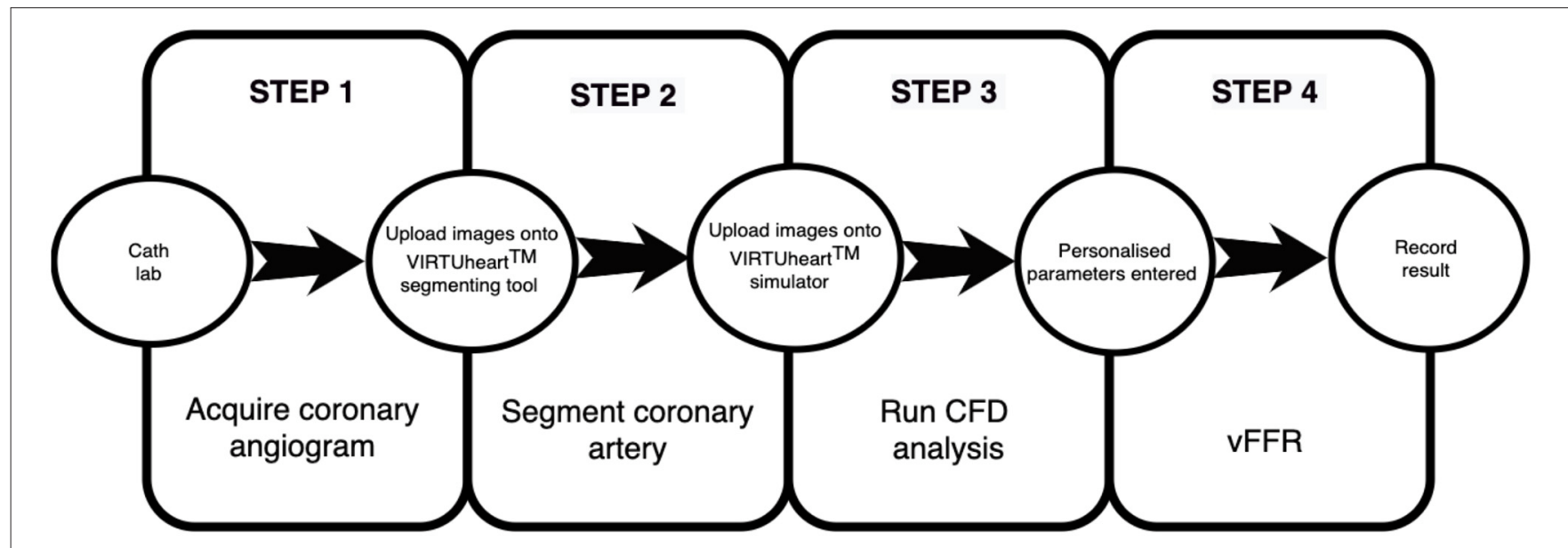

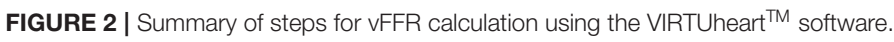




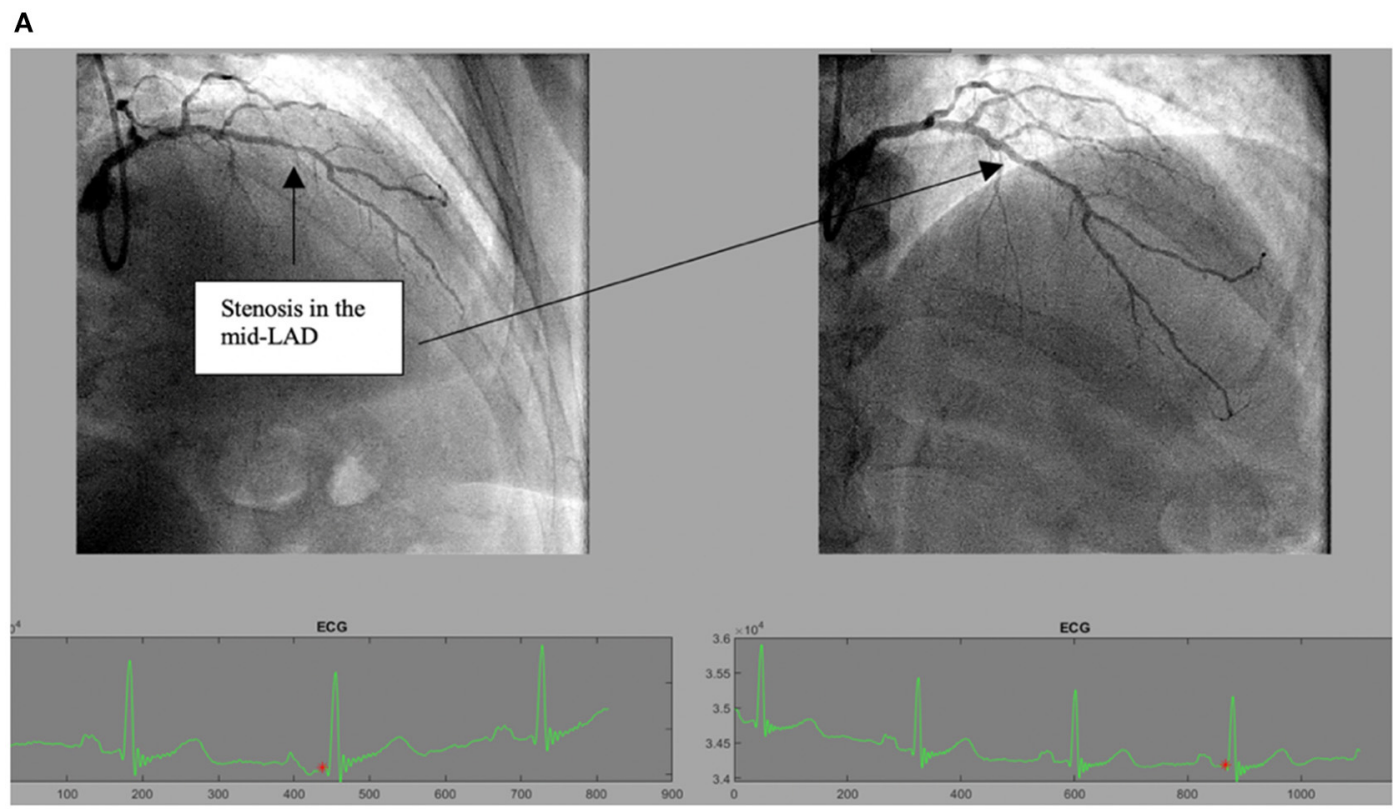

B
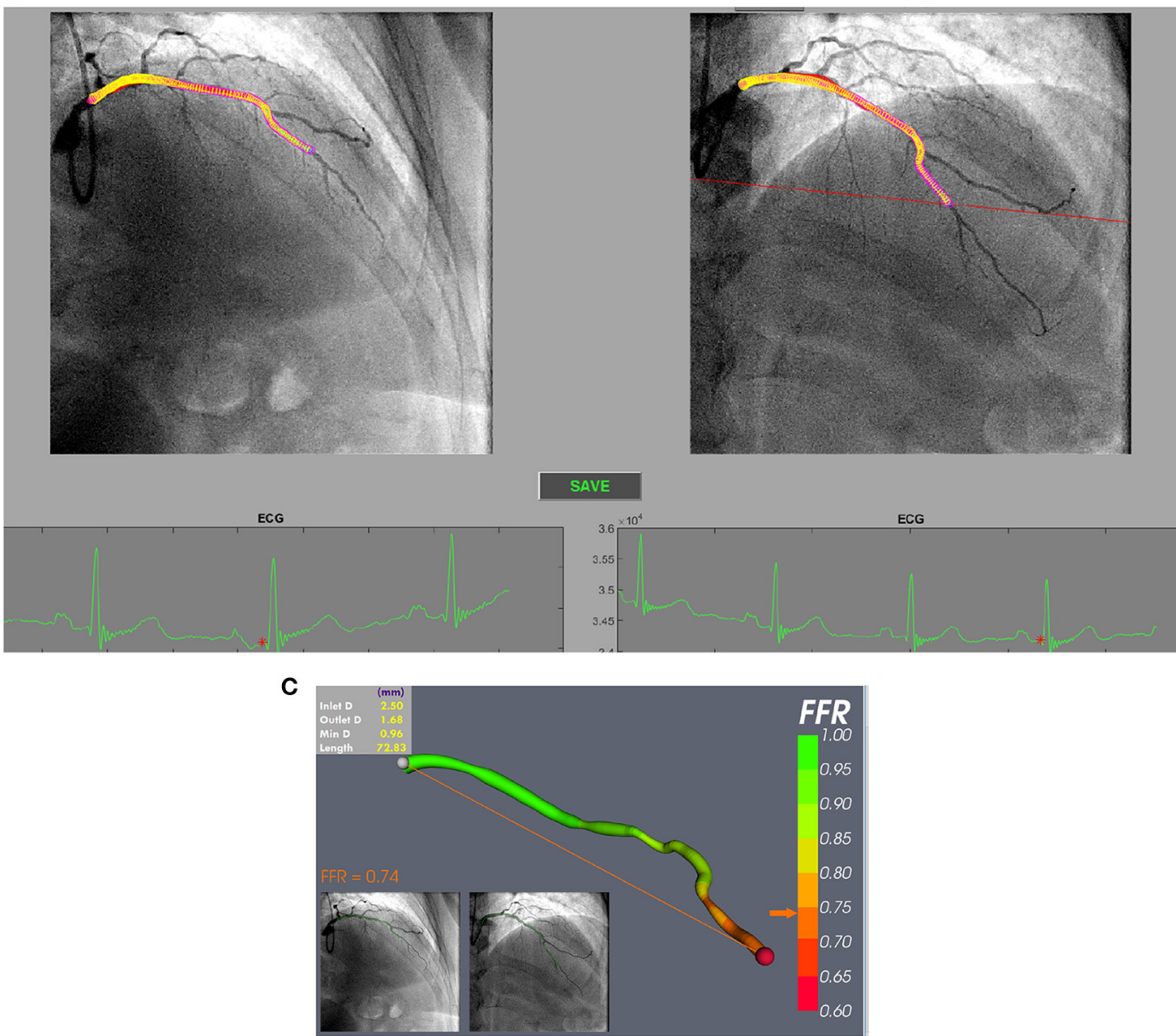

FIGURE 3 | (A) Processing selected angiogram images. Two views (at least 30 degrees apart) of the LAD are chosen at end diastole (red dot on ECG tracing) from a patient with NSTE-ACS. (B) The LAD artery is now segmented and ready for a 3D reconstruction prior to CFD simulation. (C) vFFR result after 3D reconstruction and CFD simulation showing a vFFR in the LAD of 0.74 . 
and the requirement for off-site processing (up to $24 \mathrm{~h}$ ). In the move towards timely interventional management for the ACS patient, CTCA is, therefore, generally impractical.

\section{WHAT IS VIRTUAL (V)FFR AND HOW IS IT PRODUCED?}

vFFR is a novel technique to compute FFR non-invasively, without a pressure wire, using CAG images and CFD. CFD uses the physical laws of fluid flow, obeying the conservation of mass, momentum and energy, to simulate blood flow through a conduit. Several systems have been developed. The first, VIRTUheart $^{\mathrm{TM}}$, has a high diagnostic accuracy (assessed against measured FFR) for detecting ischaemic lesions (FFR $\leq 0.80$ ), with a computing time of $<4 \mathrm{~min}(51,52)$. The VIRTUheart ${ }^{\mathrm{TM}}$ software was initially validated against mFFR in the VIRTU1 study, which analysed 35 vessels in 19 patients, revealing an accuracy of $97 \%$ (51). In a second study larger study of 101 patients, VIRTUheart ${ }^{\mathrm{TM}}$ was found to have an accuracy of $92 \%$ (53). These are similar levels of accuracy compared with other vFFR systems, although there are no published head-to-head comparisons. The two key steps in using VIRTUheart ${ }^{\mathrm{TM}}$ are obtaining an accurate 3D model of the diseased coronary artery and estimating the microvascular resistance. The former requires a good quality angiogram, with optimal opacification, minimal magnification, no "panning" and minimal vessel overlap in at least two orthogonal planes at least 30 degrees apart, ideally with an ECG trace to identify an end-diastolic frame (54). Accuracy depends upon not only precise portrayal of the lesion, but also correct estimation of the MVR. In the absence of a wire measurement, MVR is estimated by either using a population average, or some form of personalisation. A typical process is shown in Figures 2, 3. The VIRTUheart ${ }^{\mathrm{TM}}$ system can calculate the vFFR between any points and diameters, show the percentage of stenosis and even offer a "virtual stents" (53).

\section{HOW DOES THE DIFFERENT SOFTWARE FOR CALCULATING VIRTUAL FFR DIFFER FROM EACH OTHER?}

Several systems to calculate vFFR are available. Each has differing methodology. These include Quantitative Flow Ratio (QFR, Medis, Leiden, Netherlands and Pulse Medical Imaging, China) and Cardiovascular Angiographic Analysis System for Vessel FFR (CAAS-vFFR, Pie medical, Maastricht, Netherlands) based upon $3 \mathrm{D}$ quantitative coronary angiography (QCA); $\mathrm{FFR}_{\text {angio }}$ (Cathworks Ltd., Kfar-Saba, Israel) based upon 3D functional CA mapping with coronary rapid flow analysis; and Virtual Functional Assessment Index (vFAI) and Simplified Model of FFR Calculation $\left(\mathrm{FFR}_{\text {sim }}\right)$ based upon $3 \mathrm{D}$ QCA and CFD. VIRTUheart $^{\mathrm{TM}}$ is the Sheffield University system, currently confined to research use. QFR, FFR angio and CAAS-vFFR are commercially available, with QFR being the first to obtain CE-mark and FDA approval. Whilst the first QFR study was based upon CFD, subsequent studies used faster computation using an algorithm incorporating coefficients from flow data to calculate pressure drops (55). QFR employs a 3D reconstruction

TABLE 1 | Summarising CA-based FFR software.

\begin{tabular}{|c|c|c|c|c|c|}
\hline \multicolumn{6}{|c|}{ Coronary angiography based FFR technique } \\
\hline vFFR (VIRTUheart ${ }^{\mathrm{TM}}$ ) & University of Sheffield & $\begin{array}{l}\text { 3D pseudotransient CFD based on } \\
\text { Navier-Stokes equation }\end{array}$ & $\begin{array}{l}\geq 2 \text { orthogonal images } \\
\text { for each vessel }\end{array}$ & $\geq 30$ degrees & $(51,53)$ \\
\hline QFR & $\begin{array}{l}\text { Medis, Leiden, } \\
\text { Netherlands and Pulse } \\
\text { Medical Imaging, China }\end{array}$ & $\begin{array}{l}\text { Analytical equations based on laws of } \\
\text { Bernoulli and Poiseuille. Empiric flow } \\
\text { velocity (fQFR), TIMl frame } \\
\text { counting-derived contrast velocity at } \\
\text { baseline (cQFR) and under hyperaemia } \\
\text { (aQFR) }\end{array}$ & $\begin{array}{l}\geq 2 \text { orthogonal images } \\
\text { for each vessel }\end{array}$ & $\geq 25$ degrees & $(55,60,60-62)$ \\
\hline $\mathrm{FFR}_{\text {angio }}$ & $\begin{array}{l}\text { Cathworks Ltd., } \\
\text { Kfar-Saba, Israel }\end{array}$ & $\begin{array}{l}\text { Simple analytical equations based on } \\
\text { Bernoulli and Poiseuille }\end{array}$ & $\begin{array}{l}\geq 2 \text { orthogonal images } \\
\text { for each vessel }\end{array}$ & $\geq 30$ degrees & $(57,63,64)$ \\
\hline CAAS-vFFR & $\begin{array}{l}\text { Pie medical, } \\
\text { Maastricht, The } \\
\text { Netherlands }\end{array}$ & $\begin{array}{l}\text { Simple analytical equations based on } \\
\text { Bernoulli and Poiseuille }\end{array}$ & $\begin{array}{l}\geq 2 \text { orthogonal images } \\
\text { for each vessel }\end{array}$ & $\geq 30$ degrees & (59) \\
\hline vFAl & $\begin{array}{l}\text { Pie medical, } \\
\text { Maastricht, The } \\
\text { Netherlands }\end{array}$ & 3D-QCA and steady state CFD & $\begin{array}{l}\geq 2 \text { orthogonal images } \\
\text { for each vessel }\end{array}$ & $\geq 30$ degrees & (66) \\
\hline
\end{tabular}

CA, Coronary angiography; 3D, Three dimensional; QCA, Quantitative coronary angiography; VIRTUheart ${ }^{\text {TM }}$, (University of Sheffield); QFR, Quantitative flow ratio (Medis, Leiden, Netherlands and Pulse Medical Imaging, China); FFRangio, 3D functional coronary angiography mapping with coronary flow analysis (Cathworks Ltd., Kfar-Saba, Israel); CAAS-

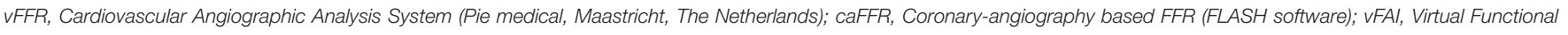
Assessment Index. 
and a QCA algorithm without reconstructing side branches (56). The software assumes that the coronary pressure remains constant in a normal coronary artery and that the distal coronary flow velocity is similar to the proximal. Based upon the mean hyperaemic velocities, the software can provide three different computation values: fixed-QFR (fQFR) based upon a flow velocity of $0.35 \mathrm{~m} / \mathrm{s}$; contrast-QFR (cQFR) applies Thrombolysis in Myocardial Infarction (TIMI) frame counting analysis at non-hyperaemic conditions; and adenosine-QFR (aQFR) uses intravenous administration of adenosine. FFR $_{\text {angio }}$ provides colour-coded vFFR by applying a rapid analysis of flow based upon Poiseuille's law. A 3D coronary tree is generated and applies epipolar ray tracing with mathematical calculation. The software identifies the stenosis automatically by systematic segment, branch and junctional analysis. A user correction is required to correct any axis displacements contributed by movement. The resistance of the coronary arterial network in each segment is estimated by the vessel diameter and length, each vessel flow being based upon the overall impact of the resistance, and the $\mathrm{FFR}_{\text {angio }}$ value being calculated as the contribution of each narrowing to the total resistance and flow (57). CAAS-vFFR uses 3D model reconstruction, the vFFR being computed by measuring the pressure drop across a lesion by using simpler physical laws of viscous resistance and separation loss effects in coronary flow behaviour (58). In addition, it incorporates patient's specific aortic pressure with the assumption that the velocity of proximal coronary artery is preserved, along with the maximum hyperaemic blood flow previously determined from clinical data (59). Table 1 summarises the various CA-based FFR techniques.

\section{WHAT IS THE EVIDENCE FOR VIRTUAL CORONARY PHYSIOLOGY IN ACS?}

The main clinical hurdle for these virtual systems is to demonstrate accuracy against measured FFR (mFFR). This is usually expressed as the new system's percentage concordance with the treatment threshold (i.e., FFR $>$ or $<0.80$ ). The QFR system, in a small study of 73 cases, disclosed accuracy of $88.3 \%$ (67) and in a larger study of 308 patients, $~ 90 \%$ (60). vFAI, which measures the average of the computed pressure ratio between distal and proximal vessel over a steady state CFD analysis has an accuracy of $88 \%$ (66). The accuracy of FFR angio was $93 \%$ in a small study (63) and $87 \%$ in a larger study of 301 patients with FFR range of $0.75-0.85$, which reflects the type of stenosis usually interrogated in real world setting (57). A sub-analysis from that study also demonstrated that FFR $_{\text {angio }}$ is more accurate than other established FFR indices like instantaneous wave-free ratio (IFR) and diastolic hyperaemia-free ratio (DFR) (68). FFR sim, in a study of 68 vessels, disclosed an accuracy of 96\% (69) which is similar to caFFR (65). The accuracy of CAAS-vFFR is $96 \%$ for vFFR measurements in their pre-defined "grey zone" $(0.77-$ $0.87)(59,70)$. This technology also showed good correlation and accuracy with IVUS confirmed significant LMS disease in 147 patients with CAD (stable and unstable) (71). The accuracy of these systems vs. FFR in patients with ACS is displayed in Table 2.

\section{WHAT ARE THE ADVANTAGES OF VFFR?}

vFFR is fast. Computation time used to be the limiting factor, but now takes only minutes. The main time-limiting factor is manual image correction prior to the CFD step. The whole process can now be done in 'real time' in the acute CCL while the patient is on the table. It does not require a pressure wire or pharmacologic hyperaemia. In addition, the $3 \mathrm{D}$ anatomical model can assist with treatment planning, selection of stent size and 'virtual coronary intervention' together with an estimate of post-stent FFR (53, $63,73)$. The same modelling technique can also predict the local haemodynamic consequence of a particular stenting strategy (74). Deploying vFFR does not supplant measured (m)FFR; if a lesion is equivocal at both angiography and vFFR, a pressure wire can still provide ultimate accuracy. There are, though, a few situations in which vFFR might actually be superior to mFFR. The first is serial lesions. Although a pressure wire "pullback" can provide some clues as to the relative significance of serial lesions, it is not infallible. In contrast, vFFR can reveal the FFR at each lesion simply by excluding the other lesion and modelling the lesion in question as if the other were not present. Of course, it can also model both together too. The second situation is when lesion complexity would make passing a pressure wire undesirable or hazardous. Another advantage is that vFFR can be used in any CCL without interventional capability. Also, the cost on a per-patient basis is likely to be low, because the business model for most commercially available systems is based upon an institutional licence.

\section{DOES VFFR HAVE ANY LIMITATIONS?}

Whilst the final coloured image appears seductive, its validity is mainly dependent upon good angiographic images, which require meticulous technique. Lesions at ostia, and at or close to the left main or a bifurcation, are difficult to model. In practise, in most CCLs, the radiographer is the most suitable professional to run the software but, even so, thorough training and practise is important. Casual users are considerably less accurate and consistent than regular users, largely due to errors in the $3 \mathrm{D}$ reconstruction; expert re-analysis of their models revealing errors that can lead to a change in the treatment decision in $37 \%$ cases (75). Although up to $50 \%$ of "standard" angiograms are unsuitable for processing, with a few simple improvements this proportion can be increased to $80 \%$ (76). This limitation is unfortunate, because it is the antithesis of measured FFR, where a scrupulous angiogram is less important. In addition, the distal outlet boundary condition is proximal to the CMV circulation, and a fundamental assumption of CMV function (maximal dilatation) is made to compute pressure from flow. The degree of CMV response to hyperaemia varies from person to person, which is why personalisation of this parameter is so important in vFFR. Also, very severe stenoses are difficult to model because the width of the lumen is less than a pixel, although in practise the likelihood is that such a lesion is physiologically significant. Finally, physiological measurement of all kinds is of most use in the assessment of angiographically intermediate lesions. So, however small the error on a vFFR 
TABLE 2 | Summarising the evidence of $\mathrm{VFFR}$ in ACS.

Summary of angiography based virtual FFR trials involving patients with ACS

\begin{tabular}{|c|c|c|c|c|c|c|c|c|c|c|c|c|c|c|c|}
\hline References & Software & Methods & $\begin{array}{l}\text { Average } \\
\text { processing } \\
\text { time (min) }\end{array}$ & $\begin{array}{l}\text { Total no of } \\
\text { patients }\end{array}$ & ACS & NSTEMI & UA & $\begin{array}{c}\text { Accuracy } \\
(\%)\end{array}$ & $\begin{array}{l}\text { Correlation } \\
\text { with FFR }\end{array}$ & $\begin{array}{l}\text { BA } \\
\text { agreement } \\
\text { with FFR }\end{array}$ & Sen $(\%)$ & $\begin{array}{l}\text { Spec } \\
(\%)\end{array}$ & PPV (\%) & NPV (\%) & AUC $(\%)$ \\
\hline Li et al. (65) & caFFR & $\begin{array}{l}\text { Prospective, } \\
\text { multi-centre, single-arm } \\
\text { study }\end{array}$ & $4.5 \pm 1.5$ & 328 & 275 & - & 275 & 95.7 & 0.89 & \pm 0.10 & 90.4 & 98.6 & 97.2 & 95 & 0.98 \\
\hline $\begin{array}{l}\text { Tröbs et al. } \\
\text { (72) }\end{array}$ & FFRangio & Retrospective analysis & $n / a$ & 73 & 22 & 4 & 18 & 90 & 0.85 & \pm 0.13 & 79 & 94 & 85 & 92 & 0.93 \\
\hline $\begin{array}{l}\text { Fearon et al. } \\
\text { (57) }\end{array}$ & $\mathrm{FFR}_{\text {angio }}$ & $\begin{array}{l}\text { Prospective, } \\
\text { multi-centre, } \\
\text { observational study }\end{array}$ & 2.7 & 382 & 126 & 28 & 98 & 93 & 0.80 & \pm 0.14 & 93.5 & 91.2 & 89 & 94 & 0.94 \\
\hline $\begin{array}{l}\text { Omori et al. } \\
(64)\end{array}$ & FFRangio & $\begin{array}{l}\text { Prospective, } \\
\text { single-centre, } \\
\text { single-arm study }\end{array}$ & $9.6 \pm 3.4$ & 50 & 22 & 7 & 15 & 92.3 & 0.83 & \pm 0.14 & 92.4 & 92.4 & $n / a$ & $n / a$ & 0.92 \\
\hline $\begin{array}{l}\text { Pellicano } \\
\text { et al. (63) }\end{array}$ & $\mathrm{FFR}_{\text {angio }}$ & $\begin{array}{l}\text { Prospective, } \\
\text { multi-centre, } \\
\text { observational study }\end{array}$ & $n / a$ & 199 & 55 & 21 & 34 & 93 & 0.88 & \pm 0.10 & 88 & 95 & $n / a$ & $n / a$ & 0.80 \\
\hline $\begin{array}{l}\text { Masdjedi } \\
\text { et al. (59) }\end{array}$ & CAAS-vFFR & $\begin{array}{l}\text { Retrospective, } \\
\text { single-centre, } \\
\text { observational study }\end{array}$ & $n / a$ & 100 & 40 & 26 & 14 & $n / a$ & 0.89 & \pm 0.07 & 97 & 74 & 85 & 89 & 0.93 \\
\hline Tu et al. (55) & QFR & $\begin{array}{l}\text { Prospective } \\
\text { observational study }\end{array}$ & $<10$ & 68 & 9 & - & 9 & 88 & 0.81 & \pm 0.11 & 78 & 93 & 82 & 91 & 0.93 \\
\hline Xu et al. (60) & QFR & $\begin{array}{l}\text { Prospective, } \\
\text { multi-centre, } \\
\text { observational study }\end{array}$ & $n / a$ & 308 & 66 & - & 66 & 92.7 & 0.86 & \pm 0.10 & 94.6 & 91.7 & 85.5 & 97.1 & 0.96 \\
\hline $\begin{array}{l}\text { Westra et al. } \\
\text { (61) }\end{array}$ & QFR & $\begin{array}{l}\text { Prospective, } \\
\text { observational } \\
\text { investigator-initiated } \\
\text { study }\end{array}$ & 5 & 272 & 6 & * & * & 86.8 & 0.83 & \pm 0.12 & 86.5 & 86.9 & 76.4 & 93 & 0.92 \\
\hline $\begin{array}{l}\text { Stähli et al. } \\
\text { (62) }\end{array}$ & QFR & $\begin{array}{l}\text { Single centre, } \\
\text { retrospective study }\end{array}$ & $n / a$ & 436 & 123 & 18 & 105 & 93.4 & 0.82 & \pm 0.08 & 75 & 97.8 & 89.3 & 94.2 & 0.86 \\
\hline $\begin{array}{l}\text { Papafaklis } \\
\text { et al. (66) }\end{array}$ & vFAl & Retrospective study & $n / a$ & 120 & 41 & 8 & 33 & 90.4 & 0.78 & \pm 0.18 & 86.2 & 87.8 & 79.9 & 93.8 & 91.9 \\
\hline
\end{tabular}

*Not specified; n/a, not reported; BA, Bland-Altman; Sen, sensitivity; Spec, specificity; PPV, positive predictive value; NPV, negative predictive value; AUC, area under the receiver operating curve; caFFR, Coronary-angiography based FFR (FLASH software); FFRangio, 3D functional coronary angiography mapping with coronary flow analysis (Cathworks Ltd., Kfar-Saba, Israel); CAAS-vFFR, Cardiovascular Angiographic Analysis System (Pie medical, Maastricht, The Netherlands); QFR, Quantitative flow ratio (Medis, Leiden, Netherlands and Pulse Medical Imaging, China); VFAI, Virtual Functional Assessment Index. 

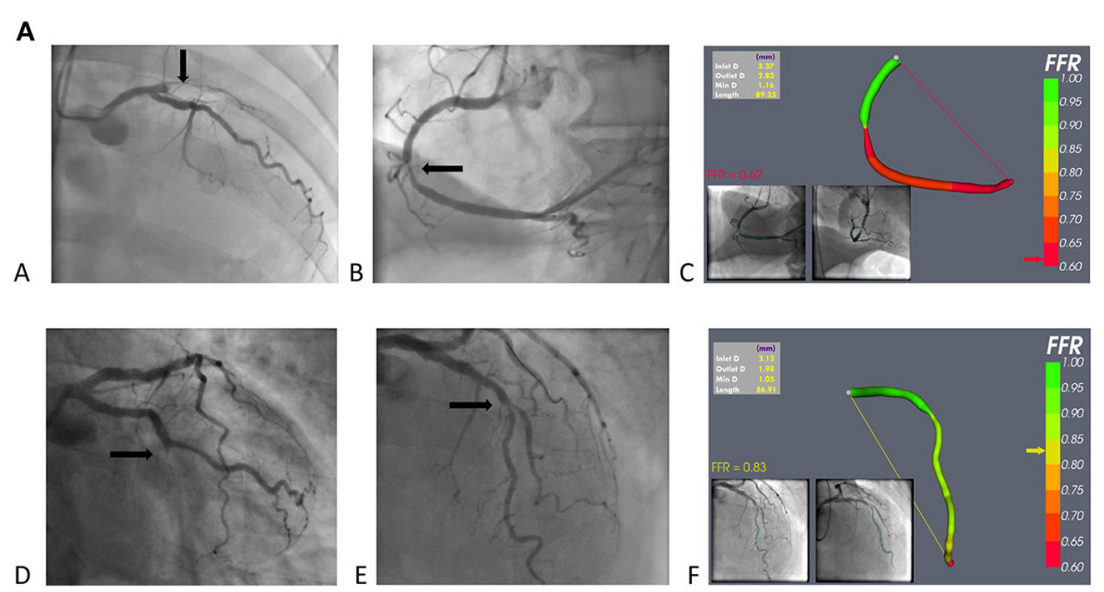

\section{B}
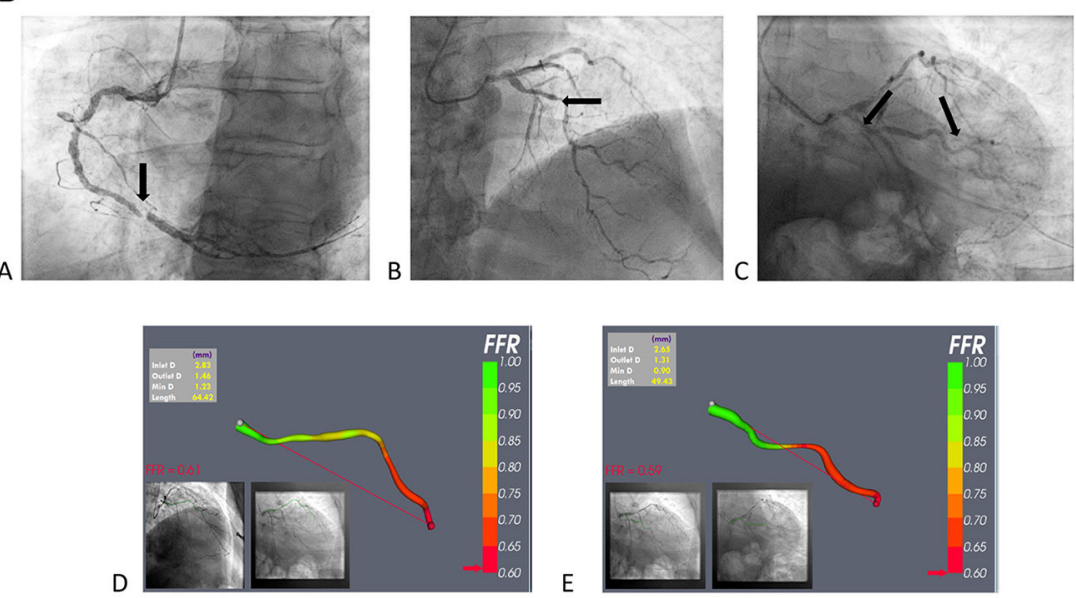

C
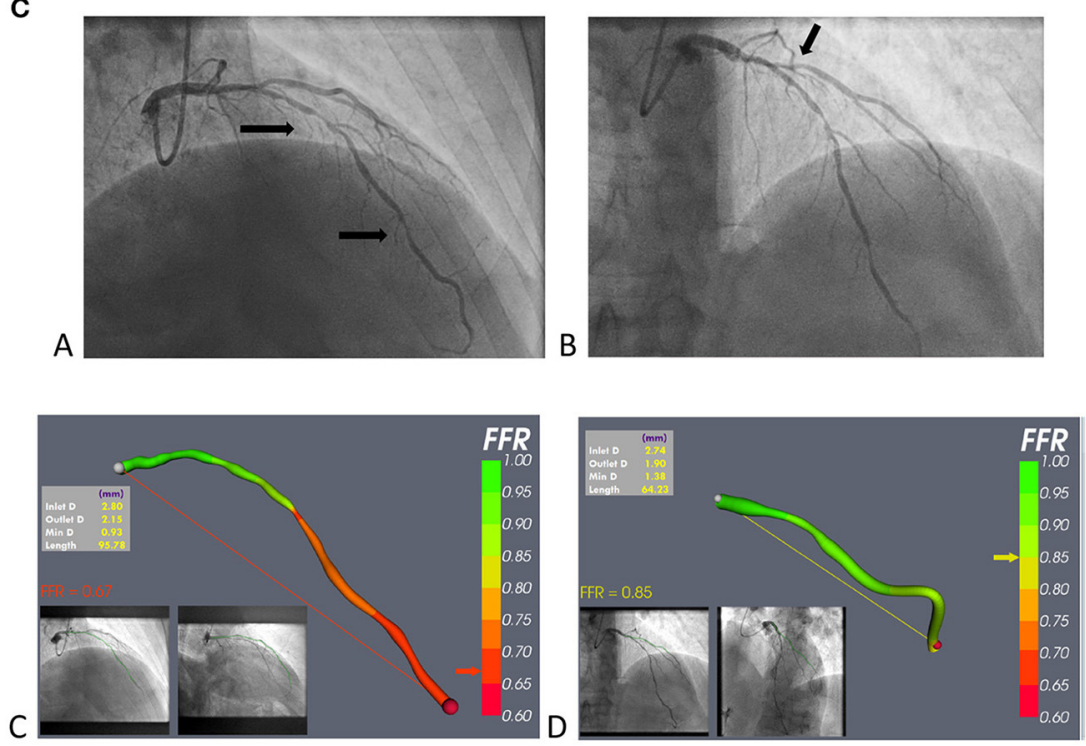

FIGURE 4 | (A) Example of VFFR application in STEMI. (a-c) A case of anterior STEMI: (a) occluded proximal LAD; (b) mid RCA non-culprit stenosis; and (c) vFFR model of the RCA lesion. (d-f) A case of infero-lateral STEMI: (d) occluded mid Cx; (e) non-culprit mid-LAD stenosis; and (f) vFFR model of the mid LAD lesion. (B) vFFR use in NSTE-ACS; case 1. (a) Severe RCA stenosis, judged to be the "culprit," and not requiring vFFR; (b) mid-LAD stenosis; (c) stenosis in the marginal branch (d) VFFR model of the LAD lesion; and (e) vFFR model of the marginal lesion. (C) vFFR use in NSTE-ACS; case 2. (a) Probable culprit LAD stenosis; (b) Probable bystander ostial diagonal stenosis; (c) vFFR model of the LAD lesion; (d) VFFR model of the D1 lesion. 


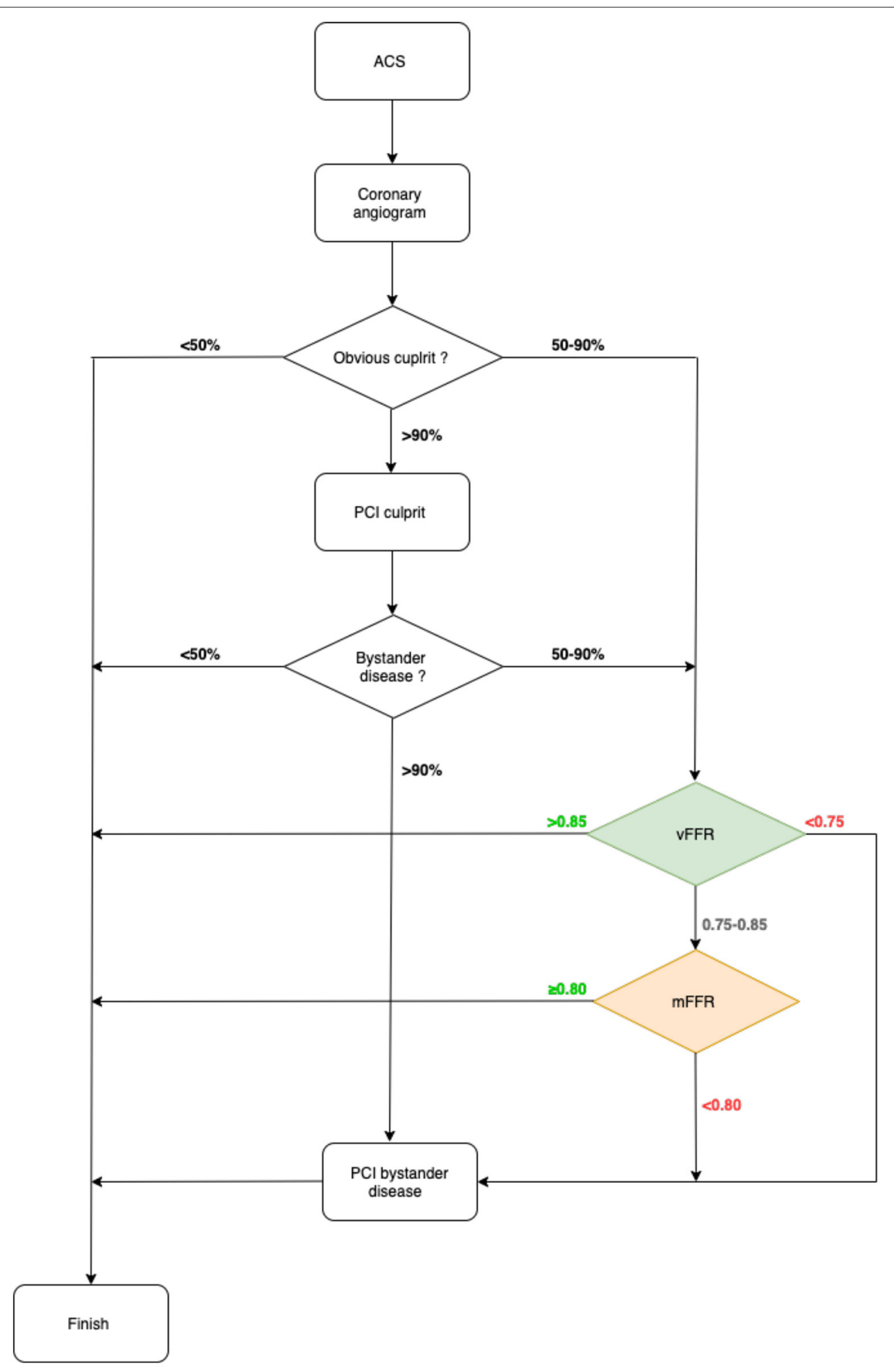

FIGURE 5 | Proposed algorithm for the use of VFFR in the management of patients with ACS.

system is, and it is usually at least \pm 0.10 , if the vFFR is calculated to be $0.75-0.85$, doubt will remain, and a measured value may be required. There is a further uncertainty, which also applies to measured FFR, which is that the physiological significance of a 
lesion, particularly in the acute patient, may not correlate with the presence of vulnerable plaque (77-79), probably explaining why long term outcomes are worse in ACS compared with CCS, even with physiological guidance. vFFR, therefore, whilst being an improvement over current management, is unlikely to provide a complete treatment strategy.

\section{POTENTIAL APPLICATION OF VFFR IN ACS}

A major attraction of vFFR for patients with ACS is that it can be used at the time of invasive management in a "one-stop shop," in which coronary anatomy can be revealed alongside lesionspecific ischaemia testing. This is both time- and cost- efficient. It could be particularly useful in the common situation of multivessel, multi-lesion disease, when the culprit is frequently not angiographically obvious. Limited data support intervention for non-culprit lesions $(14,24-26)$ but, in the "real world" and, FFR guidance being rarely used (80), vFFR would provide an opportunity to select lesions requiring intervention without instrumentation and, perhaps more importantly, eliminating those that do not. This may be particularly important in apparent triple vessel disease, in which bypass surgery could be avoided. The greatest advantage is that vFFR could bring the advantage of coronary physiology to many more patients with ACS than at present. Finally, recent CFD-based modelling innovations are able to predict microvascular resistance which is known to be of prognostic significance in ACS (81). Examples of vFFR application in patients with ACS are shown in Figure 4.

\section{HOW SHOULD VFFR BE USED IN THE ACUTE CARDIAC CATHETER LABORATORY?}

A potential algorithm for the invasive management of ACS, incorporating vFFR, is shown in Figure 5.

\section{THE INTEGRATION OF VFFR INTO STANDARD MANAGEMENT OF ACS}

Three approaches are possible. The first is simply to assume that the benefits seen in the trials of measured FFR are directly transferrable to $\mathrm{vFFR}$ and employ vFFR routinely. However, in the light of the limitations of vFFR outlined here, this assumption may be optimistic. The second would

\section{REFERENCES}

1. Green NE, Chen S-YJ, Messenger JC, Groves BM, Carroll JD. Threedimensional vascular angiography. Curr Prob Cardiol. (2004) 29:104-42. doi: 10.1016/j.cpcardiol.2004.01.002

2. Toth GG, Toth B, Johnson NP, De Vroey F, Di Serafino L, Pyxaras $S$, et al. Revascularization decisions in patients with stable angina and intermediate lesions: results of the international survey on be to interrogate existing data derived from studies employing angiographic guidance, generating post-hoc vFFRs, and reevaluating outcomes in accordance with vFFR. Because vFFR requires optimal angiographic images, however, many cases would be excluded using this approach; and it would be subject to the limitations of retrospective studies. The third would be to undertake prospective, randomised, controlled trials of vFFRvs. CAG- guidance with clinical and health economic endpoints. A multi-centre RCT of 3,860 patients is currently investigating the superiority and efficacy of QFR- vs. CAG-guidance (82). Ultimately, endorsement in clinical guidelines will be required. Whichever approach is adopted, this technology is here to stay.

\section{LEARNING POINTS}

1. Measured FFR is under-used for cost and logistic reasons.

2. Virtual (computed) FFR (vFFR) can be constructed from a coronary angiogram and does not need a pressure wire.

3. vFFR can be applied to intermediate lesions in ACS patients.

4. It can provide treatment guidance while the patient is in the cardiac catheter laboratory.

5. vFFR requires meticulous coronary angiography.

\section{AUTHOR CONTRIBUTIONS}

$\mathrm{HH}$ is supervised by JG, who leads the research team and designed the study. $\mathrm{HH}$ is responsible for conducting the research, recruiting patients, processing the cases, and analysing the data and results. VR, GP, and RH are responsible for coding, building the software as well as the main driving force behind the technological aspects, and improving the vFFR tool. MG, PDM, RG, GW, MM, TN, and PL contributed towards reviewing the paper with feedback and corrections prior to the final copy. All authors contributed to the article and approved the submitted version.

\section{FUNDING}

$\mathrm{HH}, \mathrm{MG}$, GP, and RG were supported by the British Heart Foundation (TG/19/1/34451, FS/16/48/32306). PDM was supported by a Wellcome Trust Clinical Research Career Development Fellowship (214567/Z/18/Z). GW was supported by the Engineering and Physical Sciences Research Council (199760907). For the purpose of Open Access, the author has applied a CC BY public copyright license to any Author Accepted Manuscript version arising from this submission. 
versus fractional flow reserve for native coronary narrowings of moderate severity. Am J Cardiol. (2002) 90:210-5. doi: 10.1016/S0002-9149(02)02456-6

5. Alexander Y, Osto E, Schmidt-Trucksäss A, Shechter M, Trifunovic D, Duncker DJ, et al. Endothelial function in cardiovascular medicine: a consensus paper of the European Society of Cardiology Working Groups on Atherosclerosis and Vascular Biology, Aorta and Peripheral Vascular Diseases, Coronary Pathophysiology and Microcirculation, and Thrombosis. Cardiovasc Res. (2021) 117:29-42. doi: 10.1093/cvr/cvaa085

6. Windecker S, Kolh P, Alfonso F, Collet JP, Cremer J, Falk V, et al. 2014 ESC/EACTS Guidelines on myocardial revascularization: the task force on myocardial revascularization of the European Society of Cardiology (ESC) and the European Association for Cardio-Thoracic Surgery (EACTS) Developed with the special contribution of the European Association of Percutaneous Cardiovascular Interventions (EAPCI). Eur Heart J. (2014) 3:2541-619. doi: 10.1093/eurheartj/ehu278

7. Zimmermann FM, Ferrara A, Johnson NP, van Nunen LX, Escaned J, Albertsson P, et al. Deferral vs. performance of percutaneous coronary intervention of functionally non-significant coronary stenosis: 15year follow-up of the DEFER trial. Eur Heart J. (2015) 36:3182-8. doi: 10.1093/eurheartj/ehv452

8. Shaw LJ, Berman DS, Maron DJ, Mancini GBJ, Hayes SW, Hartigan PM, et al. Optimal medical therapy with or without percutaneous coronary intervention to reduce ischemic burden: results from the clinical outcomes utilizing revascularization and aggressive drug evaluation (COURAGE) trial nuclear substudy. Circulation. (2008) 117:1283-91. doi: 10.1161/CIRCULATIONAHA.107.743963

9. De Bruyne B, Fearon WF, Pijls NHJ, Barbato E, Tonino P, Piroth Z, et al. Fractional flow reserve-guided PCI for stable coronary artery disease. $N$ Engl J Med. (2014) 371:1208-17. doi: 10.1056/NEJMoa1408758

10. Pijls NHJ, Fearon WF, Tonino PAL, Siebert U, Ikeno F, Bornschein B, et al. Fractional flow reserve versus angiography for guiding percutaneous coronary intervention in patients with multivessel coronary artery disease: 2-year follow-up of the fame (fractional flow reserve versus angiography for multivessel evaluation) study. J Am Coll Cardiol. (2010) 56:177-84. doi: 10.1016/j.jacc.2010.04.012

11. Sels J-WEM, Tonino PAL, Siebert U, Fearon WF, Van't Veer M, De Bruyne $B$, et al. Fractional flow reserve in unstable angina and non-ST-segment elevation myocardial infarction. JACC Cardiovasc Interv. (2011) 4:1183-9. doi: 10.1016/j.jcin.2011.08.008

12. Fearon WF, Bornschein B, Tonino PAL, Gothe RM, Bruyne BD, Pijls NHJ, et al. Economic evaluation of fractional flow reserve-guided percutaneous coronary intervention in patients with multivessel disease. Circulation. (2010) 122:2545-50. doi: 10.1161/CIRCULATIONAHA.109.925396

13. Omran J, Enezate T, Abdullah O, Al-Dadah A, Walters D, Patel M, et al. Outcomes of fractional flow reserve-guided percutaneous coronary interventions in patients with acute coronary syndrome. Catheter Cardiovasc Interv. (2019) 96:ccd.28611. doi: 10.1002/ccd.28611

14. Layland J, Oldroyd KG, Curzen N, Sood A, Balachandran K, Das R, et al. Fractional flow reserve vs. angiography in guiding management to optimize outcomes in non-ST-segment elevation myocardial infarction: the British Heart Foundation FAMOUS-NSTEMI randomized trial. Eur Heart J. (2015) 36:100-11. doi: 10.1093/eurheartj/ehu338

15. Nam J, Briggs A, Layland J, Oldroyd KG, Curzen N, Sood A, et al. Fractional flow reserve (FFR) versus angiography in guiding management to optimise outcomes in non-ST segment elevation myocardial infarction (FAMOUS-NSTEMI) developmental trial: cost-effectiveness using a mixed trial- and model-based methods. Cost Eff Resour Alloc. (2015) 13:19. doi: 10.1186/s12962-015-0045-9

16. Lopez-Palop R, Carrillo P, Torres F, Lozano I, Frutos A, Avanzas P, et al. Resultados del empleo de la reserva fraccional de flujo en la valoración de lesiones no causales en el síndrome coronario agudo. Revista Española de Cardiología. (2012) 65:164-70. doi: 10.1016/j.recesp.2011.09.020

17. Briasoulis A, Palla M, Mostafa A, Afonso L, Grines C. Fractional flow-guided management in patients with acute coronary syndromes: a systematic review and meta-analysis. Int J Cardiol. (2015) 187:334-7. doi: 10.1016/j.ijcard.2015.03.325

18. Van Belle E, Baptista S-B, Raposo L, Henderson J, Rioufol G, Santos L, et al. Impact of routine fractional flow reserve on management decision and 1-year clinical outcome of patients with acute coronary syndromes: PRIME-FFR (insights from the POST-IT [Portuguese study on the evaluation of FFR-guided treatment of coronary disease] and R3F [French FFR registry] integrated multicenter registries - implementation of FFR [fractional flow reserve] in routine practice). Circ Cardiovasc Interv. (2017) 10:296. doi: 10.1161/CIRCINTERVENTIONS.116.004296

19. Lee JM, Choi KH, Koo B-K, Shin E-S, Nam C-W, Doh J-H, et al. Prognosis of deferred non-culprit lesions according to fractional flow reserve in patients with acute coronary syndrome. EuroIntervention. (2017) 13:e1112-9. doi: 10.4244/EIJ-D-17-00110

20. Martins JL, Afreixo V, Santos J, Gonçalves L. Fractional flow reserve-guided strategy in acute coronary syndrome. A systematic review and meta-analysis. Arquivos Brasil Cardiol. (2018) 111:542-50. doi: 10.5935/abc.20180170

21. Liou KP, Ooi S-YM, Hoole SP, West NEJ. Fractional flow reserve in acute coronary syndrome: a meta-analysis and systematic review. Open Heart. (2019) 6:e000934. doi: 10.1136/openhrt-2018-000934

22. Collet J-P, Thiele H, Barbato E, Barthélémy O, Bauersachs J, Bhatt DL, et al. 2020 ESC Guidelines for the management of acute coronary syndromes in patients presenting without persistent ST-segment elevation. Eur Heart J. (2021) 42:1289-367. doi: 10.1093/eurheartj/ehaa575

23. Neumann F-J, Sousa-Uva M, Ahlsson A, Alfonso F, Banning AP, Benedetto U, et al. 2018 ESC/EACTS Guidelines on myocardial revascularization. Eur Heart J. (2019) 40:87-165. doi: 10.1093/eurheartj/ehy855

24. Mehta SR, Wood DA, Storey RF, Mehran R, Bainey KR, Nguyen H, et al. Complete Revascularization with Multivessel PCI for Myocardial Infarction. N Engl J Med. (2019) 381:1411-21. doi: 10.1056/NEJMoal 907775

25. Smits PC, Abdel-Wahab M, Neumann F-J, Boxma-de Klerk BM, Lunde $\mathrm{K}$, Schotborgh $\mathrm{CE}$, et al. Fractional flow reserve-guided multivessel angioplasty in myocardial infarction. N Engl J Med. (2017) 376:1234-44. doi: 10.1056/NEJMoa1701067

26. Engstrøm T, Kelbæk H, Helqvist S, Høfsten DE, Kløvgaard L, Holmvang L, et al. Complete revascularisation versus treatment of the culprit lesion only in patients with ST-segment elevation myocardial infarction and multivessel disease (DANAMI-3-PRIMULTI): an open-label, randomised controlled trial. Lancet. (2015) 386:665-71. doi: 10.1016/S0140-6736(15)60648-1

27. Puymirat E, Cayla G, Simon T, Steg PG, Montalescot G, Durand-Zaleski I, et al. Multivessel PCI guided by FFR or angiography for myocardial infarction. N Engl J Med. (2021) 385:297-308. doi: 10.1056/NEJMoa2104650

28. Dattilo PB, Prasad A, Honeycutt E, Wang TY, Messenger JC. Contemporary patterns of fractional flow reserve and intravascular ultrasound use among patients undergoing percutaneous coronary intervention in the United States. J Am Coll Cardiol. (2012) 60:2337-9. doi: 10.1016/j.jacc.2012.08.990

29. Pijls NHJ, Tanaka N, Fearon WF. Functional assessment of coronary stenoses: can we live without it? Eur Heart J. (2013) 34:1335-44. doi: 10.1093/eurheartj/ehs436

30. Ntalianis A, Sels J-W, Davidavicius G, Tanaka N, Muller O, Trana C, et al. Fractional flow reserve for the assessment of nonculprit coronary artery stenoses in patients with acute myocardial infarction. JACC Cardiovasc Interv. (2010) 12:1274-81. doi: 10.1016/j.jcin.2010.08.025

31. De Bruyne B, Pijls NHJ, Bartunek J, Kulecki K, Bech J-W, De Winter H, et al. Fractional flow reserve in patients with prior myocardial infarction. Circulation. (2001) 104:157-62. doi: 10.1161/01.CIR.104.2.157

32. Samady H, Lepper W, Powers ER, Wei K, Ragosta M, Bishop GG, et al. Fractional flow reserve of infarct-related arteries identifies reversible defects on noninvasive myocardial perfusion imaging early after myocardial infarction. J Am Coll Cardiol. (2006) 47:2187-93. doi: $10.1016 /$ j.jacc.2006.01.065

33. van de Hoef TP, Nolte F, Rolandi MC, Piek JJ, van den Wijngaard JPHM, Spaan JAE, et al. Coronary pressure-flow relations as basis for the understanding of coronary physiology. J Mol Cell Cardiol. (2012) 52:786-93. doi: 10.1016/j.yjmcc.2011.07.025

34. Briceno N, Lumley M, Perera D. Fractional flow reserve: conundrums, controversies and challenges. Interv Cardiol. (2015) 7:543-52. doi: $10.2217 /$ ica. 15.43

35. Vranckx P, Cutlip DE, McFadden EP, Kern MJ, Mehran R, Muller O. Coronary pressure-derived fractional flow reserve measurements: recommendations for standardization, recording, and reporting as a core laboratory technique. 
Proposals for integration in clinical trials. Circ Cardiovasc Interv. (2012) 5:312-7. doi: 10.1161/CIRCINTERVENTIONS.112.968511

36. Matsumuto H, Nakatsuma K, Shimada T. Effect of caffeine on intravenous adenosine-induced hyperemia in fractional flow reserve measurement. $J$ Invasive Cardiol. (2020) 26.

37. Leonardi RA, Townsend JC, Patel CA, Wolf BJ, Todoran TM, Fernandes $\mathrm{VL}$, et al. Left ventricular end-diastolic pressure affects measurement of fractional flow reserve. Cardiovasc Revascular Med. (2013) 14:218-22. doi: 10.1016/j.carrev.2013.06.001

38. Petraco R, Sen S, Nijjer S, Echavarria-Pinto M, Escaned J, Francis DP, et al. Fractional flow reserve-guided revascularization. JACC Cardiovasc Interv. (2013) 6:222-5. doi: 10.1016/j.jcin.2012.10.014

39. De Bruyne B, Pijls NHJ, Heyndrickx GR, Hodeige D, Kirkeeide R, Gould KL. Pressure-derived fractional flow reserve to assess serial epicardial stenoses: theoretical basis and animal validation. Circulation. (2000) 101:1840-7. doi: 10.1161/01.CIR.101.15.1840

40. Beigel R, Oieru D, Goitein O, Chouraqui P, Konen E, Shamiss A, et al. Usefulness of routine use of multidetector coronary computed tomography in the "fast track" evaluation of patients with acute chest pain. Am J Cardiol. (2009) 103:1481-6. doi: 10.1016/j.amjcard.2009.02.009

41. Roobottom C, Mitchell G, Iyengar S. The role of non-invasive imaging in patients with suspected acute coronary syndrome. BJR. (2011) 84:S269-79. doi: $10.1259 / \mathrm{bjr} / 57084479$

42. Hollander JE, Chang AM, Shofer FS, McCusker CM, Baxt WG, Litt HI. Coronary computed tomographic angiography for rapid discharge of low-risk patients with potential acute coronary syndromes. Ann Emerg Med. (2009) 53:295-304. doi: 10.1016/j.annemergmed.2008.09.025

43. Hoffmann U, Bamberg F, Chae CU, Nichols JH, Rogers IS, Seneviratne SK, et al. Coronary computed tomography angiography for early triage of patients with acute chest pain. J Am Coll Cardiol. (2009) 53:1642-50. doi: 10.1016/j.jacc.2009.01.052

44. Roffi M, Patrono C, Collet J-P, Mueller C, Valgimigli M, Andreotti F, et al. 2015 ESC Guidelines for the management of acute coronary syndromes in patients presenting without persistent ST-segment elevation task force for the management of acute coronary syndromes in patients presenting without persistent ST-segment elevation of the european society of cardiology (ESC). Eur Heart J. (2016) 37:267-315. doi: 10.1093/eurheartj/ehv320

45. Gray AJ, Roobottom C, Smith JE, Goodacre S, Oatey K, O'Brien R, et al. The RAPID-CTCA trial (Rapid Assessment of Potential Ischaemic Heart Disease with CTCA) - a multicentre parallel-group randomised trial to compare early computerised tomography coronary angiography versus standard care in patients presenting with suspected or confirmed acute coronary syndrome: study protocol for a randomised controlled trial. Trials. (2016) 17:579. doi: 10.1186/s13063-016-1717-2

46. Taylor CA, Fonte TA, Min JK. Computational fluid dynamics applied to cardiac computed tomography for noninvasive quantification of fractional flow reserve. J Am Coll Cardiol. (2013) 61:2233-41. doi: 10.1016/j.jacc.2012.11.083

47. Koo B-K, Erglis A, Doh J-H, Daniels DV, Jegere S, Kim H-S, et al. Diagnosis of ischemia-causing coronary stenoses by noninvasive fractional flow reserve computed from coronary computed tomographic angiograms. J Am Coll Cardiol. (2011) 58:1989-97. doi: 10.1016/j.jacc.2011.06.066

48. Nørgaard BL, Leipsic J, Gaur S, Seneviratne S, Ko BS, Ito H, et al. Diagnostic performance of noninvasive fractional flow reserve derived from coronary computed tomography angiography in suspected coronary artery disease. $J$ Am Coll Cardiol. (2014) 63:1145-55. doi: 10.1016/j.jacc.2013.11.043

49. Brady P, Kelion A, Hyde T, Barnes E, Rahbi H, Beale A, et al. CT coronary angiography with HeartFlow ${ }^{\circledR}$ : a user's perspective. Br J Cardiol. (2019) 26:105-9. doi: 10.5837/bjc.2019.029

50. Morris PD, Curzen N, Gunn JP. Angiography-derived fractional flow reserve: more or less physiology? JAHA. (2020) 9:586. doi: 10.1161/JAHA.119.015586

51. Morris PD, Ryan D, Morton AC, Lycett R, Lawford PV, Hose DR, et al. Virtual fractional flow reserve from coronary angiography: modeling the significance of coronary lesions. JACC Cardiovasc Interv. (2013) 6:149-57. doi: 10.1016/j.jcin.2012.08.024

52. Morris PD, van de Vosse FN, Lawford PV, Hose DR, Gunn JP. "Virtual" (Computed) fractional flow reserve. JACC Cardiovasc Interv. (2015) 8:1009-17. doi: 10.1016/j.jcin.2015.04.006
53. Gosling RC, Morris PD, Silva Soto DA, Lawford PV, Hose DR, Gunn JP. Virtual coronary intervention. JACC Cardiovasc Imag. (2019) 12:865-72. doi: $10.1016 /$ j.jcmg.2018.01.019

54. Ghobrial M, Haley HA, Gosling R, Rammohan V, Lawford PV, Hose DR, et al. The new role of diagnostic angiography in coronary physiological assessment. Heart. (2021) 107:783-9. doi: 10.1136/heartjnl-2020-318289

55. Tu S, Barbato E, Köszegi Z, Yang J, Sun Z, Holm NR, et al. Fractional flow reserve calculation from 3-dimensional quantitative coronary angiography and timi frame count: a fast computer model to quantify the functional significance of moderately obstructed coronary arteries. JACC Cardiovasc Interv. (2014) 7:768-77. doi: 10.1016/j.jcin.2014.03.004

56. Tu S, Xu L, Ligthart J, Xu B, Witberg K, Sun Z, et al. In vivo comparison of arterial lumen dimensions assessed by co-registered three-dimensional (3D) quantitative coronary angiography, intravascular ultrasound and optical coherence tomography. Int J Cardiovasc Imaging. (2012) 28:1315-27. doi: 10.1007/s10554-012-0016-6

57. Fearon WF, Achenbach S, Engstrom T, Assali A, Shlofmitz R, Jeremias A, et al. Accuracy of fractional flow reserve derived from coronary angiography. Circulation. (2019) 139:477-84. doi: 10.1161/CIRCULATIONAHA.118.037350

58. Gould KLMD, Kelley KORN, Bolson ELMS. Experimental validation of quantitative coronary arteriography for determining pressureflow characteristics of coronary stenosis. Circulation. (1982) 66:930-7. doi: 10.1161/01.CIR.66.5.930

59. Masdjedi K, van Zandvoort LJC, Balbi MM, Gijsen FJH, Ligthart JMR, Rutten MCM, et al. Validation of a three-dimensional quantitative coronary angiography-based software to calculate fractional flow reserve: the FAST study. Euro Interv. (2020) 16:591-9. doi: 10.4244/EIJ-D-19-00466

60. Xu B, Tu S, Qiao S, Qu X, Chen Y, Yang J, et al. Diagnostic accuracy of angiography-based quantitative flow ratio measurements for online assessment of coronary stenosis. J Am Coll Cardiol. (2017) 70:3077-87. doi: 10.1016/j.jacc.2017.10.035

61. Westra J, Andersen BK, Campo G, Matsuo H, Koltowski L, Eftekhari A, et al. Diagnostic performance of in-procedure angiography-derived quantitative flow reserve compared to pressure-derived fractional flow reserve: the FAVOR II Europe-Japan study. J Am Heart Assoc. (2018) 7:603. doi: 10.1161/JAHA.118.009603

62. Stähli BE, Erbay A, Steiner J, Klotsche J, Mochmann H-C, Skurk C, et al. Comparison of resting distal to aortic coronary pressure with angiography-based quantitative flow ratio. Int J Cardiol. (2019) 279:12-7. doi: 10.1016/j.ijcard.2018.11.093

63. Pellicano M, Lavi I, De Bruyne B, Vaknin-Assa H, Assali A, Valtzer $\mathrm{O}$, et al. Validation study of image-based fractional flow reserve during coronary angiography. Circ Cardiovasc Interv. (2017) 10:259. doi: 10.1161/CIRCINTERVENTIONS.116.005259

64. Omori H, Witberg G, Kawase Y, Tanigaki T, Okamoto S, Hirata $\mathrm{T}$, et al. Angiogram based fractional flow reserve in patients with dual/triple vessel coronary artery disease. Int J Cardiol. (2019) 283:17-22. doi: 10.1016/j.ijcard.2019.01.072

65. Li J, Gong Y, Wang W, Yang Q, Liu B, Lu Y, et al. Accuracy of computational pressure-fluid dynamics applied to coronary angiography to derive fractional flow reserve: FLASH FFR. Cardiovasc Res. (2020) 116:1349-56. doi: 10.1093/cvr/cvz289

66. Papafaklis MI, Muramatsu T, Ishibashi Y, Lakkas LS, Nakatani S, Bourantas $\mathrm{CV}$, et al. Fast virtual functional assessment of intermediate coronary lesions using routine angiographic data and blood flow simulation in humans: comparison with pressure wire - fractional flow reserve. EuroIntervention. (2014) 10:574-83. doi: 10.4244/EIJY14M07_01

67. Tu S, Westra J, Yang J, von Birgelen C, Ferrara A, Pellicano M, et al. Diagnostic accuracy of fast computational approaches to derive fractional flow reserve from diagnostic coronary angiography. JACC Cardiovasc Interv. (2016) 9:2024-35. doi: 10.1016/j.jcin.2016.07.013

68. Johnson NP, Matsumura M, Achenbach S, Engstrom T, Assali A, Jeremias A, et al. Angiography-derived fractional flow reserve versus invasive nonhyperemic pressure ratios. J Am Coll Cardiol. (2019) 73:3232-3. doi: 10.1016/j.jacc.2019.04.017

69. Tar B, Jenei C, Dezsi CA, Bakk S, Beres Z, Santa J, et al. Less invasive fractional flow reserve measurement from 3-dimensional quantitative 
coronary angiography and classic fluid dynamic equations. EuroIntervention. (2018) 14:942-50. doi: 10.4244/EIJ-D-17-00859

70. Neleman T, Masdjedi K, Van Zandvoort LJC, Tomaniak M, Ligthart JMR, Witberg KT, et al. Extended validation of novel 3D quantitative coronary angiography-based software to calculate vFFR. JACC Cardiovasc Imag. (2020). 14:S1936878X20307233. doi: 10.1016/j.jcmg.2020.08.006

71. Tomaniak M, Masdjedi K, Zandvoort LJ, van, Neleman T, Forero MNT, Vermaire A, et al. Correlation between 3D-QCA based FFR and quantitative lumen assessment by IVUS for left main coronary artery stenoses. Catheter Cardiovasc Interv. (2021) 94:E495-501. doi: 10.1002/ccd.29151

72. Tröbs M, Achenbach S, Röther J, Redel T, Scheuering M, Winneberger D, et al. Comparison of fractional flow reserve based on computational fluid dynamics modeling using coronary angiographic vessel morphology versus invasively measured fractional flow reserve. Am J Cardiol. (2016) 117:29-35. doi: 10.1016/j.amjcard.2015.10.008

73. Gosling DRC, Adam Z, Barmby DS, Iqbal J, Morgan KP, Richardson JD, et al. The impact of virtual fractional flow reserve and virtual coronary intervention upon treatment decisions in the cardiac catheter laboratory. Can J Cardiol. (2021) S0828282X21003019. doi: 10.1016/j.cjca.2021.06.004. [Epub ahead of print].

74. Morris PD, Iqbal J, Chiastra C, Wu W, Migliavacca F, Gunn JP. Simultaneous kissing stents to treat unprotected left main stem coronary artery bifurcation disease; stent expansion, vessel injury, hemodynamics, tissue healing, restenosis, and repeat revascularization. Catheter Cardiovasc Interv. (2018) 92:E381-92. doi: 10.1002/ccd.27640

75. Lal K, Gunn J, Morris P, Gosling R, Lawford P, Hose R, et al. 17 Computational modelling of fractional flow reserve from coronary angiography: expert training required. In: Imaging. BMJ Publishing Group Ltd and British Cardiovascular Society (2019). p. A15-6. Available online at: http://heart.bmj. com/lookup/doi/10.1136/heartjnl-2019-BCS.16 (accessed June 16, 2020).

76. Preston H, Stroud S, Lai K, Gosling R, Morris P, Hose DR, et al. Abstract 9797: Feasibility of Coronary Angiogram-based Computational Modelling of Fractional Flow Reserve in Everyday Practice. Circulation. (2019) 140:A9797.

77. Xie Y, Mintz GS, Yang J, Doi H, Iñiguez A, Dangas GD, et al. Clinical outcome of nonculprit plaque ruptures in patients with acute coronary syndrome in the PROSPECT study. JACC Cardiovasc Imag. (2014) 7:397-405. doi: 10.1016/j.jcmg.2013.10.010

78. Calvert PA, Obaid DR, O'Sullivan M, Shapiro LM, McNab D, Densem CG, et al. Association between IVUS findings and adverse outcomes in patients with coronary artery disease. JACC Cardiovasc Imag. (2011) 4:894-901. doi: 10.1016/j.jcmg.2011.05.005

79. Bom MJ, van der Heijden DJ, Kedhi E, van der Heyden J, Meuwissen M, Knaapen P, et al. Early detection and treatment of the vulnerable coronary plaque: can we prevent acute coronary syndromes? Circ Cardiovasc Imag. (2017) 10:973. doi: 10.1161/CIRCIMAGING.116.005973

80. Ludman P. BCIS Audit of Adult Cardiovascular Interventions Performed from 1st of April 2018 to 31st if March. (2019). BCIS audit report 20182019. (2019). Available online at: https://www.bcis.org.uk/education/bcisaudit-report-2018-19/ (accessed June 29, 2020).

81. Morris PD, Gosling R, Zwierzak I, Evans H, Aubiniere-Robb L, Czechowicz $\mathrm{K}$, et al. A novel method for measuring absolute coronary blood flow and microvascular resistance in patients with ischaemic heart disease. Cardiovasc Res. (2021) 117:1567-77. doi: 10.1093/cvr/cvaa220

82. Xu B. Comparison of Quantitative Flow Ratio Guided and Angiography Guided Percutaneous InterVention in Patients With cORonary Artery Disease (The FAVOR III China Study). (2020). Report No.: NCT03656848. Available online at: https://clinicaltrials.gov/ct2/show/NCT03656848 (accessed January 21, 2021).

Conflict of Interest: The authors declare that the research was conducted in the absence of any commercial or financial relationships that could be construed as a potential conflict of interest.

Publisher's Note: All claims expressed in this article are solely those of the authors and do not necessarily represent those of their affiliated organizations, or those of the publisher, the editors and the reviewers. Any product that may be evaluated in this article, or claim that may be made by its manufacturer, is not guaranteed or endorsed by the publisher.

Copyright (c) 2021 Haley, Ghobrial, Morris, Gosling, Williams, Mills, Newman, Rammohan, Pederzani, Lawford, Hose and Gunn. This is an open-access article distributed under the terms of the Creative Commons Attribution License (CC BY). The use, distribution or reproduction in other forums is permitted, provided the original author(s) and the copyright owner(s) are credited and that the original publication in this journal is cited, in accordance with accepted academic practice. No use, distribution or reproduction is permitted which does not comply with these terms. 